\title{
CASOS CONFIRMADOS DE CÂNCER NO COLO DO ÚTERO NO BRASIL ENTRE OS ANOS DE 2010 A 2014
}

\section{ARTIGO ORIGINAL}

FARIAS, Rafaela Santos ${ }^{1}$, FACCO, Lucas², FECURY, Amanda Alves ${ }^{3}$, ARAÚJO, Maria Helena Mendonça de ${ }^{4}$, OLIVEIRA, Euzébio de ${ }^{5}$, DENDASCK, Carla Viana ${ }^{6}$, SOUZA, Keulle Oliveira da ${ }^{7}$, DIAS, Claudio Alberto Gellis de Mattos ${ }^{8}$

FARIAS, Rafaela Santos. Et al. Casos confirmados de câncer no colo do útero no Brasil entre os anos de 2010 a 2014. Revista Científica Multidisciplinar Núcleo do Conhecimento. Ano 05, Ed. 11, Vol. 25, pp. 93-104. Novembro de 2020. ISSN: 2448-0959, Link de acesso: https://www.nucleodoconhecimento.com.br/saude/colodo-utero, DOI: 10.32749/nucleodoconhecimento.com.br/saude/colo-do-utero

\section{RESUMO}

O exame Papanicolau (PCCU) é um exame ginecológico realizado em mulheres, a fim de detectar danos no colo do útero. Alterações podem ser observadas como uma desordem do tecido que o compõe. O objetivo deste trabalho é mostrar casos confirmados de câncer no colo do útero no brasil entre os anos de 2010 a 2014. A pesquisa foi realizada com dados retirados do DATASUS (http://datasus.saude.gov.br). Quando existe um bom desempenho para prevenir uma doença considerada grave, o resultado é satisfatório e eficaz. Através dos

\footnotetext{
${ }^{1}$ Técnica em Mineração, egressa do Instituto Federal do Amapá (IFAP).

2 Discente do Curso de Medicina da Universidade Federal do Amapá (UNIFAP).

${ }^{3}$ Biomédica, Doutora em Doenças Tropicais, Professora e pesquisadora do Curso de Medicina da Universidade Federal do Amapá (UNIFAP).

${ }^{4}$ Médica, Professora e pesquisadora do Curso de Medicina da Universidade Federal do Amapá (UNIFAP).

${ }^{5}$ Biólogo, Doutor em Doenças Topicais, Professor e pesquisador do Curso de Educação Física da Universidade Federal do Pará (UFPA).

${ }^{6}$ Teóloga, Doutora em Psicanálise, pesquisadora do Centro de Pesquisa e Estudos Avançados- CEPA.

${ }^{7}$ Socióloga, Mestranda em Estudos Antrópicos na Amazônia, Integrante do Grupo de Pesquisa "Laboratório de Educação, Meio Ambiente e Saúde" (LEMAS/UFPA).

${ }^{8}$ Biólogo, Doutor em Teoria e Pesquisa do Comportamento, Professor e pesquisador do Programa de PósGraduação em Educação Profissional e Tecnológica (PROFEPT), Instituto Federal do Amapá (IFAP).
}

RC: 66619

Disponível em: https://www.nucleodoconhecimento.com.br/saude/colo-do-utero 
resultados obtidos pela análise dos dados entre os anos de 2010 a 2014 respectivamente, conclui-se que ao passar dos anos a procura pela realização do exame aumentou gradativamente, porém alguns aspectos persistiram, como a vergonha de realizar o exame pcc, medo, dores, entre outros. Contudo os resultados mostraram alto índice realização de exames na região sudeste e menor índice na região norte, com baixa divulgação e pouca conscientização para as mulheres da região norte. Portanto a divulgação, conscientização e realização do exame citopatológico é muito importante para a prevenção do câncer do colo uterino, que hoje em dia é a maior causa de mortalidade entre as mulheres brasileiras

Palavras-Chave: Epidemiologia, câncer colo uterino, PCCU, Citopatologia.

\section{INTRODUÇÃO}

Exames preventivos são realizados para identificar possíveis doenças e tratá-las em seu início (BRASIL, 2013). O exame Papanicolau (PCCU) é um exame ginecológico realizado em mulheres, a fim de detectar danos no colo do útero, que podem se tornar prejudiciais à saúde (TEIXEIRA et al., 2015). Este exame serve para descobrir precocemente alterações no colo do útero. Ele auxilia no diagnóstico precoce do câncer feminino, podendo ser tratado no seu estado inicial, evitando assim aumento no índice de mortalidade entre as mulheres (ARAÚJO et al., 2016). Esse exame deve ser realizado por mulheres que têm uma vida sexualmente ativa ou que são maiores de 18 anos. Ele se baseia em recolher e analisar amostras do colo do útero para identificar o câncer (BARBEIRO et al., 2009).

Alterações podem ser observadas como uma desordem do tecido que compõe o colo do útero. Esta desordem pode ser subdividida em graus. O Grau 1 (I) se dá quando ocorre uma leve desordenação das células, comprometendo pequenas partes do tecido. Quando essa desordenação celular alcança até três quartos do tecido, considera-se no Grau 2 (II). No Grau 3 (III) observa-se que o arranjo das células está totalmente desordenado, identificando o chamado câncer de colo uterino (MENETRIER et al., 2016).

RC: 66619

Disponível em: https://www.nucleodoconhecimento.com.br/saude/colo-do-utero 
A quantidade de exames PCCU realizados no Brasil, em 2010, eram da ordem aproximada de 10 milhões exames ao ano. Esta quantidade de exames papanicolau variou entre as regiões brasileiras. Na região norte foram feitos 603.738 (Seiscentos e três mil setecentos e trinta e oito) exames. A região nordeste realizou 2.616.344 (Dois milhões seiscentos e dezesseis mil trezentos e quarenta e quatro) exames. $\mathrm{Na}$ região centro-oeste foram feitos 745.875 (Setecentos e quarenta e cinco mil oitocentos e setenta e cinco) exames. Na região sudeste foram examinados 4.703.400 (Quatro milhões setecentos e três mil e quatrocentos) pessoas. Na região sul foram realizados 1.606.119 (Um milhão seiscentos e seis mil cento e dezenove) exames (BORTOLON et al., 2012).

A quantidade de exames PCCU realizados em 2010 na região norte do Brasil varia conforme cada estado que a compõe. No Amapá foram realizados 19.657 (Dezenove mil seiscentos e cinquenta) exames. No Acre foram feitos 53.754 (Cinquenta e três mil setecentos e cinquenta e quatro) exames. No Amazonas 134.268 (Cento e trinta e quatro mil duzentos e sessenta e oito) exames realizados. No estado do Pará foram 191.298 (Cento e noventa e um mil duzentos e noventa e oito) exames. Em Rondônia 92.085 (Noventa e dois mil e oitenta e dois) exames realizados. No estado de Roraima foram feitos 28.614 (Vinte e oito mil seiscentos e quatorze) exames. Já em Tocantins foram realizados 84.062 (Oitenta e quatro mil e sessenta e dois) exames (BORTOLON et al., 2012).

\section{OBJETIVO}

Mostrar casos confirmados de câncer no colo do útero no brasil entre os anos de 2010 a 2014.

\section{MÉTODO}

A pesquisa foi realizada com dados retirados do DATASUS (http://datasus.saude.gov.br) seguindo as seguintes etapas: primeiro selecionou- se a Aba "acesso à informação" em seguida a opção "informações de saúde(TABNET)"

RC: 66619

Disponível em: https://www.nucleodoconhecimento.com.br/saude/colo-do-utero 
logo depois a sub-opção "Epidemiológica e Morbidade" após acessou- se o grupo de opção "Câncer de colo de útero e de mama (SISCOLO/SISMAMA). Em seguida selecionou- se o ícone "Câncer de colo do útero e de mama - desde 2000". Abriu-se a aba "Siscolo 4.00 ou superior" e se selecionou a opção "Exame citopatologico cervico-vaginal e microflora-procedimento 12.011.01-0". Em seguida clicou-se em "Brasil/regiões". Para a coleta de dados selecionou- se no campo linha a opção "Ano de competência". No campo conteúdo foi selecionada a opção "Quantidade de Exames". No campo coluna as opções foram "Não ativa"; "ano de competência"; Ano de competência"; "Reg.residência"; "Escolaridade"; "Cor/Raça"; "Dentro da normalidade"; "Interv coleta"; "Interv resultado"; "Citopatol.Anterior"; e "Tempo Últ.Prevent". Para todas as opções coletou- se dados de 2010 à 2014. Selecionouse ainda no campo linha a opção "Mês/Ano de competência" no campo coluna a opção "Faixa etária" e no campo conteúdo a opção "Quantidade de Exames", para os mesmos anos. A compilação dos dados foi feita dentro do aplicativo Excel, componente do pacote Office da Microsoft Corporation. A pesquisa bibliográfica foi realizada em artigos científicos, utilizando-se para a busca computadores do laboratório de informática do Instituto Federal de Educação, Ciência e Tecnologia do Amapá, Câmpus Macapá, situado na: Rodovia BR 210 KM 3, s/n - Bairro Brasil Novo, CEP: 68.909-398, Macapá, Amapá, Brasil.

\section{RESULTADOS}

A figura 1 mostra a porcentagem de exames Papanicolau (PCCU) realizados no Brasil entre 2010 e 2014. Entre 2010 e 2013 a quantidade de exames se manteve praticamente estável. Em 2014 os dados mostram que houve uma diminuição acentuada na realização dos exames no país.

RC: 66619

Disponível em: https://www.nucleodoconhecimento.com.br/saude/colo-do-utero 
Figura 1 Mostra a porcentagem de exames Papanicolau (PCCU) realizados no Brasil entre 2010 e 2014.

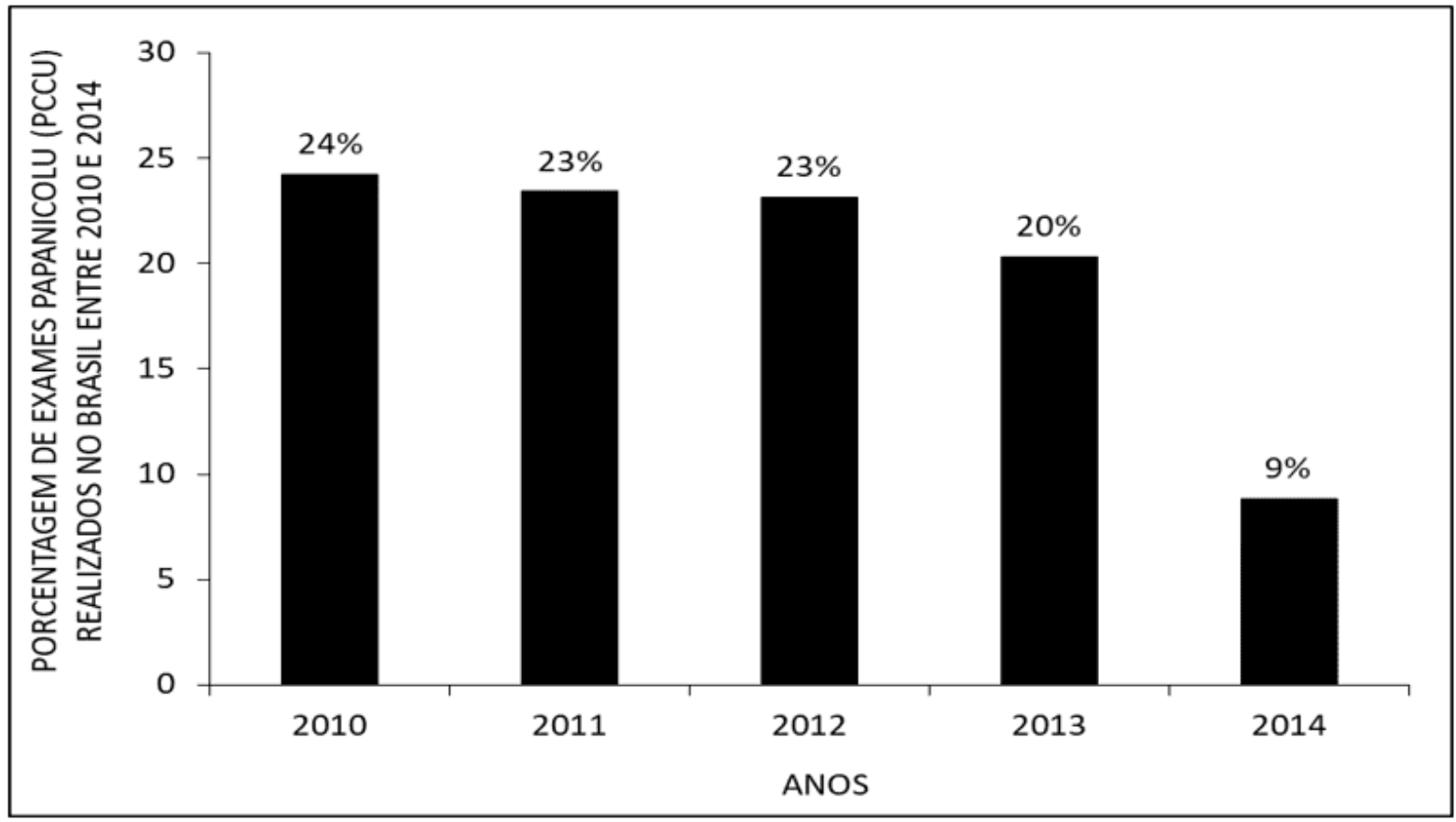

A figura 2 mostra a porcentagem de exames Papanicolau (PCCU) realizados no Brasil entre 2010 e 2014, por regiões do país. Mostrando maior índice de exames realizados na região sudeste e uma menor quantidade de exames nas regiões nordeste, sul, centro-oeste e norte, respectivamente.

RC: 66619

Disponível em: https://www.nucleodoconhecimento.com.br/saude/colo-do-utero 
Figura 2 Mostra a porcentagem de exames Papanicolau (PCCU) realizados no Brasil entre 2010 e 2014, por regiões do país.

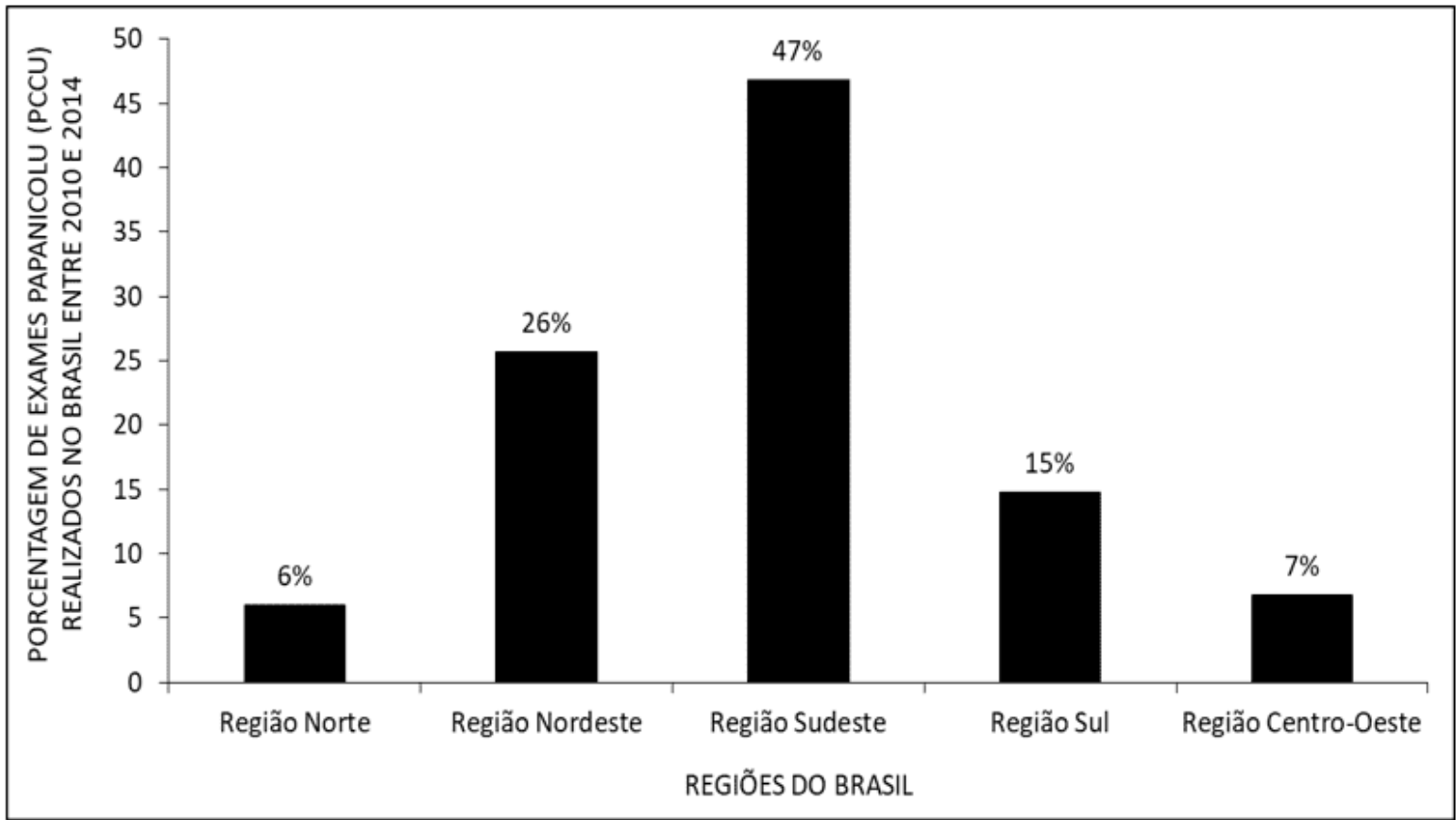

A figura 3 mostra a porcentagem de exames Papanicolau (PCCU) realizados no Brasil entre 2010 e 2014, de acordo com a faixa etária. Os dados mostram que a maior quantidade de exames é realizado entre mulheres de 30 a 39 anos. A menor está na faixa etária de mulheres até os 19 anos.

RC: 66619

Disponível em: https://www.nucleodoconhecimento.com.br/saude/colo-do-utero 
Figura 3 Mostra a porcentagem de exames Papanicolau (PCCU) realizados no Brasil entre 2010 e 2014. de acordo com a faixa etária.

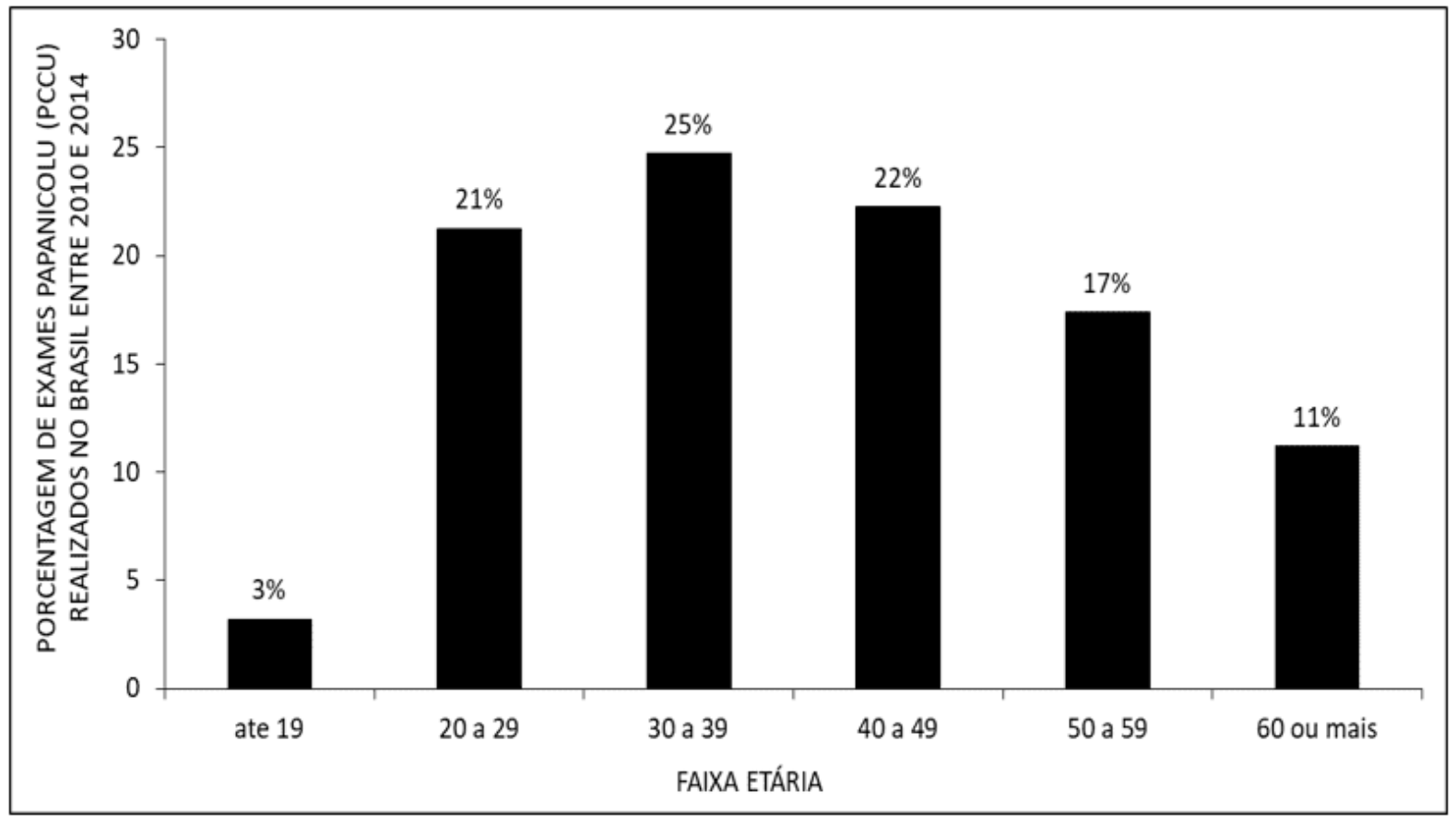

A figura 4 mostra a porcentagem de exames Papanicolau (PCCU) realizados no Brasil entre 2010 e 2014, por escolaridade. Mostrando que a maioria das mulheres que realizam o exame tem ensino fundamental incompleto. Enquanto a menor quantidade tem ensino superior completo.

RC: 66619

Disponível em: https://www.nucleodoconhecimento.com.br/saude/colo-do-utero 
Figura 4 Mostra a porcentagem de exames Papanicolau (PCCU) realizados no Brasil entre 2010 e 2014, por escolaridade.

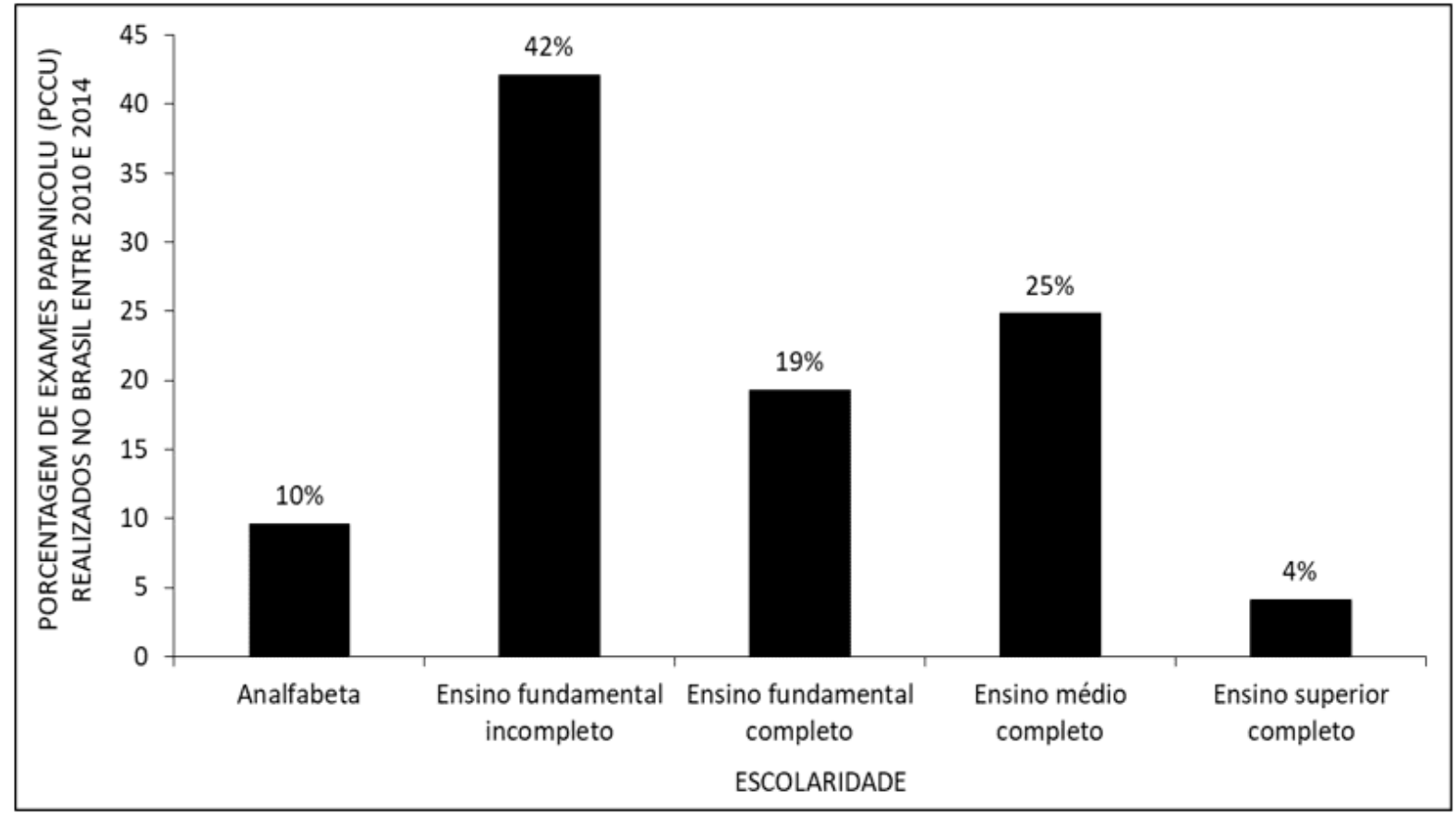

A figura 5 mostra a porcentagem de exames Papanicolau (PCCU) realizados no Brasil entre 2010 e 2014, por etnia. As mulheres de etnia branca e parda realizam uma grande quantidade de exames comparadas às mulheres das etnias preta, amarela e indígena.

RC: 66619

Disponível em: https://www.nucleodoconhecimento.com.br/saude/colo-do-utero 
Figura 5 Mostra a porcentagem de exames Papanicolau (PCCU) realizados no Brasil entre 2010 e 2014, por etnia.

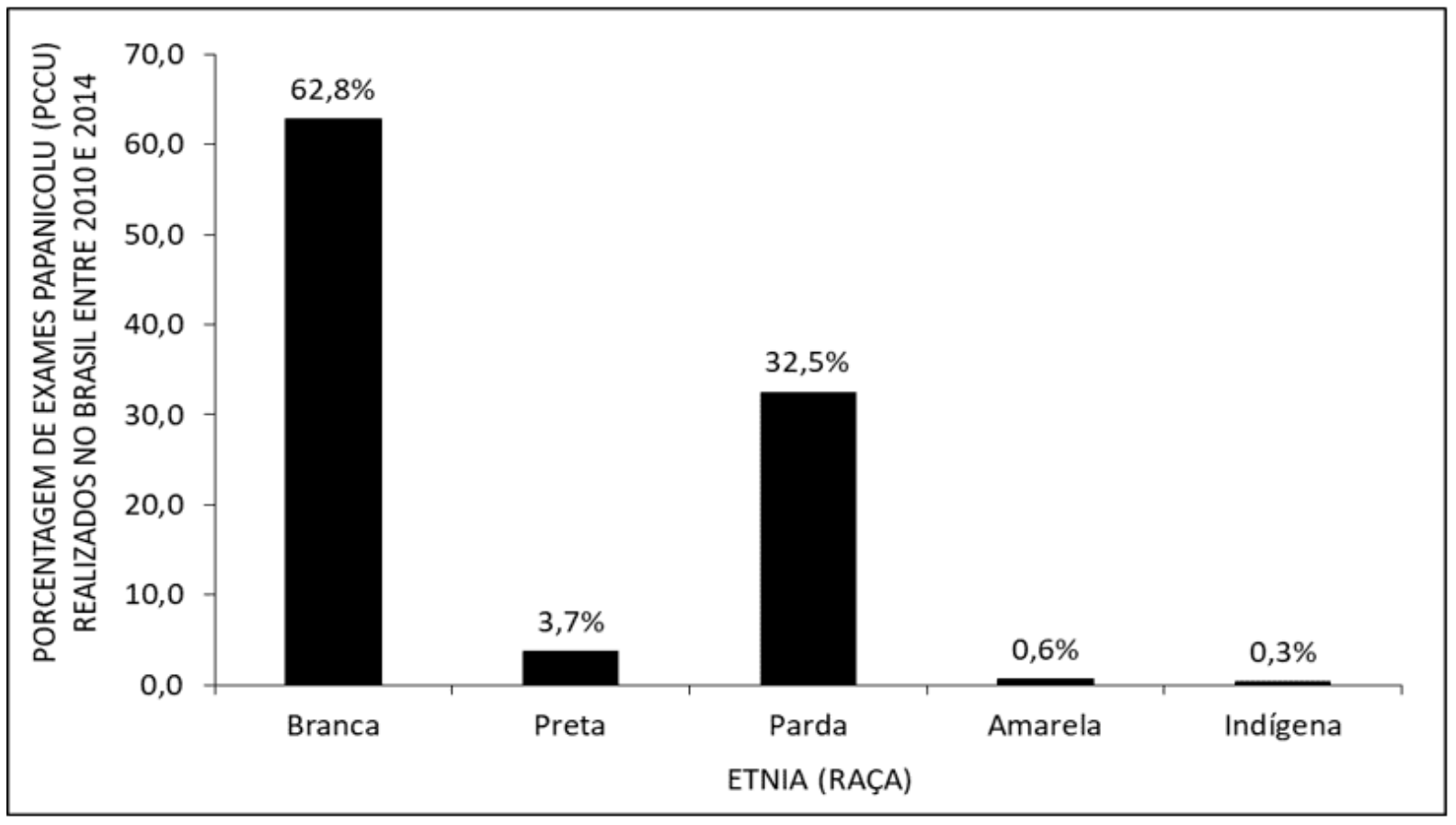

A figura 6 mostra a porcentagem de exames Papanicolau (PCCU) realizados no Brasil, dentro da normalidade, entre 2010 e 2014. Entre os exames realizados os dados mostram que a maioria não se encontra dentro da normalidade.

RC: 66619

Disponível em: https://www.nucleodoconhecimento.com.br/saude/colo-do-utero 
Figura 6 Mostra a porcentagem de exames Papanicolau (PCCU) realizados no Brasil, dentro da normalidade, entre 2010 e 2014.

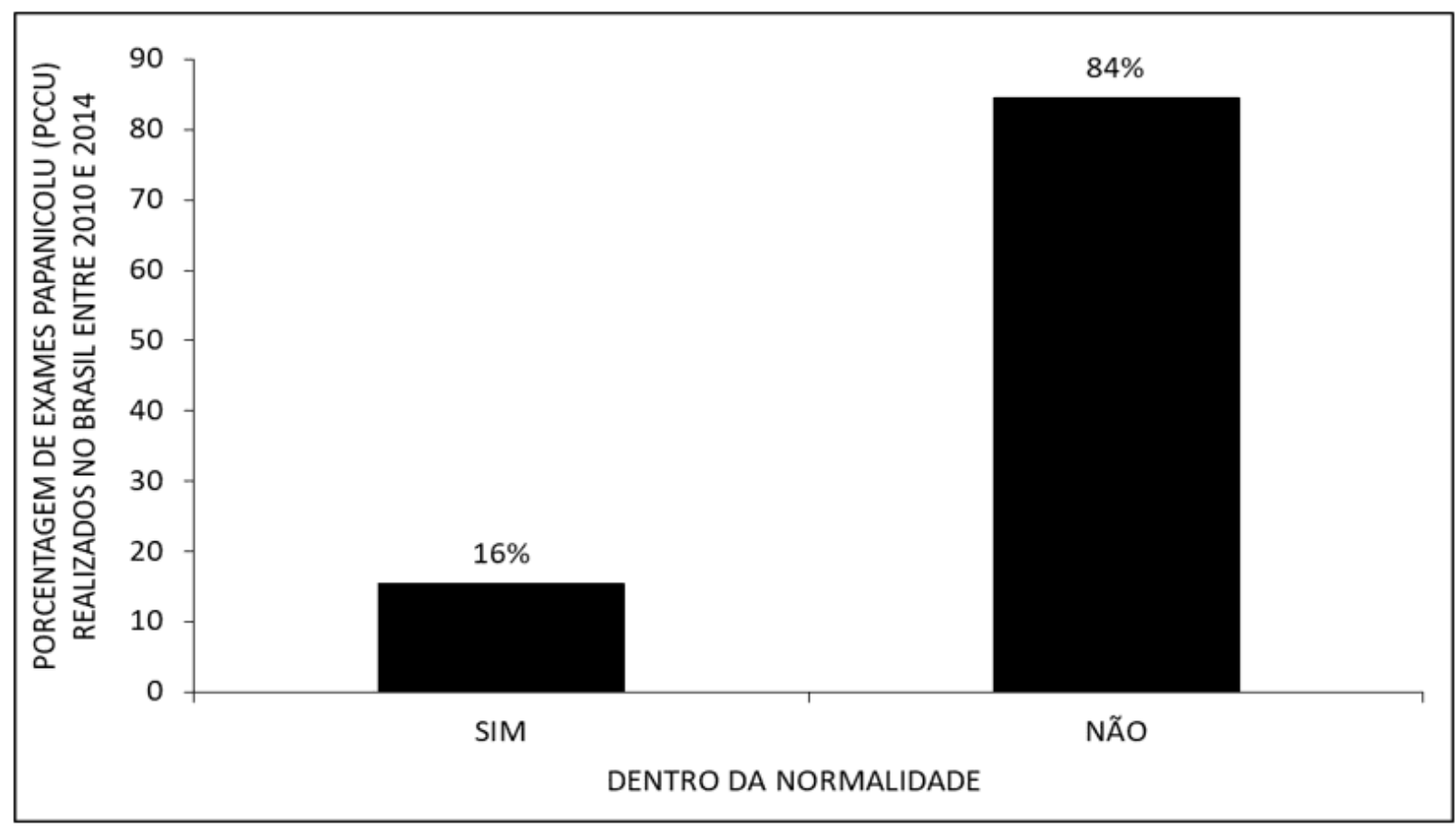

A figura 7 mostra a porcentagem de exames Papanicolau (PCCU) realizados no Brasil entre 2010 e 2014, por intervalo de coleta. Os exames foram coletados na sua maioria no intervalo de até 10 dias, enquanto a menor quantidade tem um intervalo de coleta maior que 30 dias.

RC: 66619

Disponível em: https://www.nucleodoconhecimento.com.br/saude/colo-do-utero 
Figura 7 Mostra a porcentagem de exames Papanicolau (PCCU) realizados no Brasil entre 2010 e 2014 , por intervalo de coleta.

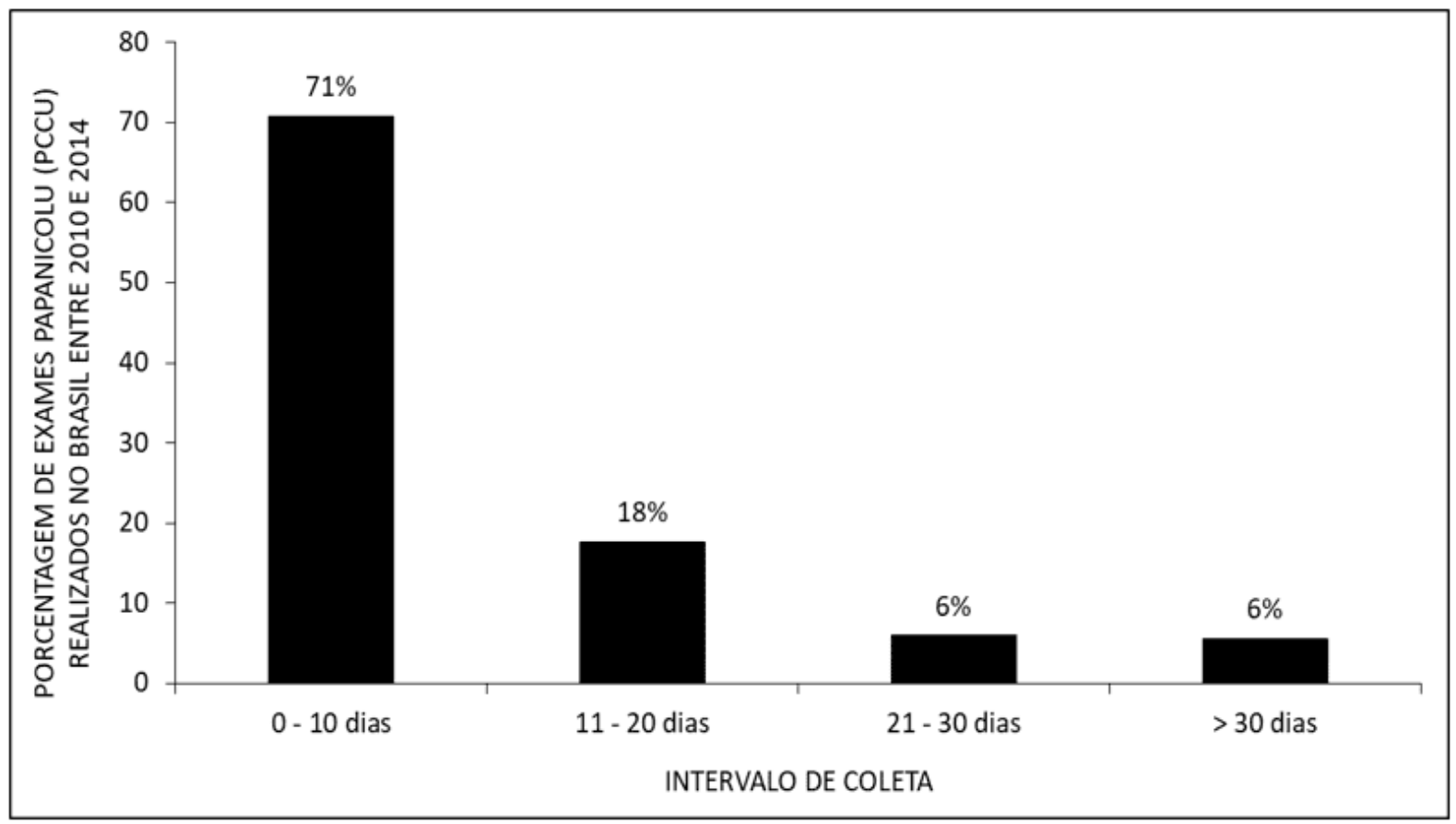

A figura 8 mostra a porcentagem de exames Papanicolau (PCCU) realizados no Brasil entre 2010 e 2014, por intervalo de resultado. Mostrando que a maioria dos resultados foram liberados em até 10 dias. Enquanto a menor quantidade em mais de 30 dias.

RC: 66619

Disponível em: https://www.nucleodoconhecimento.com.br/saude/colo-do-utero 
Figura 8 Mostra a porcentagem de exames Papanicolau (PCCU) realizados no Brasil entre 2010 e 2014, por intervalo de resultado.

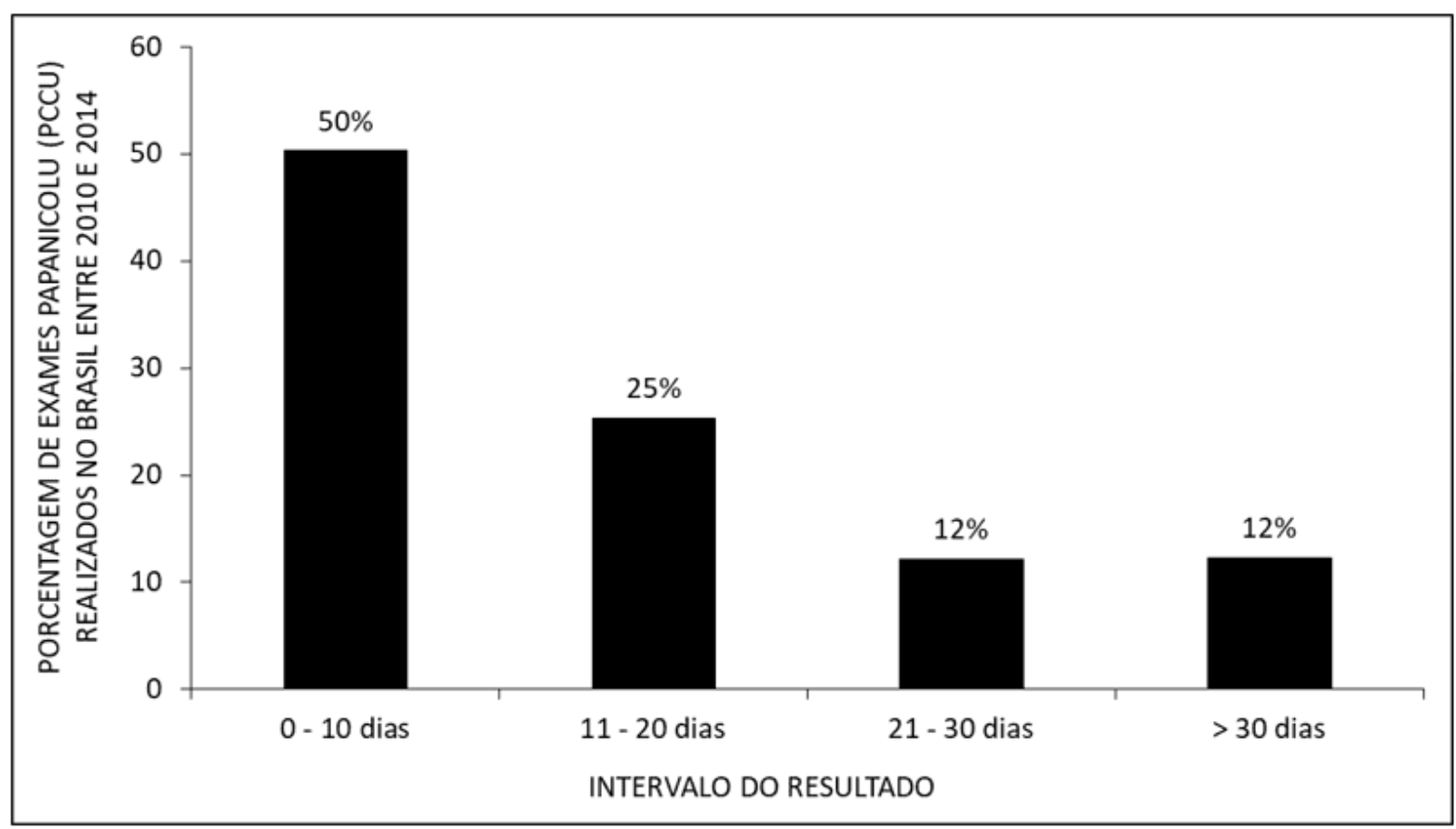

A figura 9 mostra a porcentagem de exames Papanicolau (PCCU) realizados no Brasil entre 2010 e 2014, de acordo com realização de exame citológico anterior. A maioria das mulheres pesquisadas realizaram exames anteriormente.

RC: 66619

Disponível em: https://www.nucleodoconhecimento.com.br/saude/colo-do-utero 
Figura 9 Mostra a porcentagem de exames Papanicolau (PCCU) realizados no Brasil entre 2010 e 2014, de acordo com realização de exame citológico anterior.

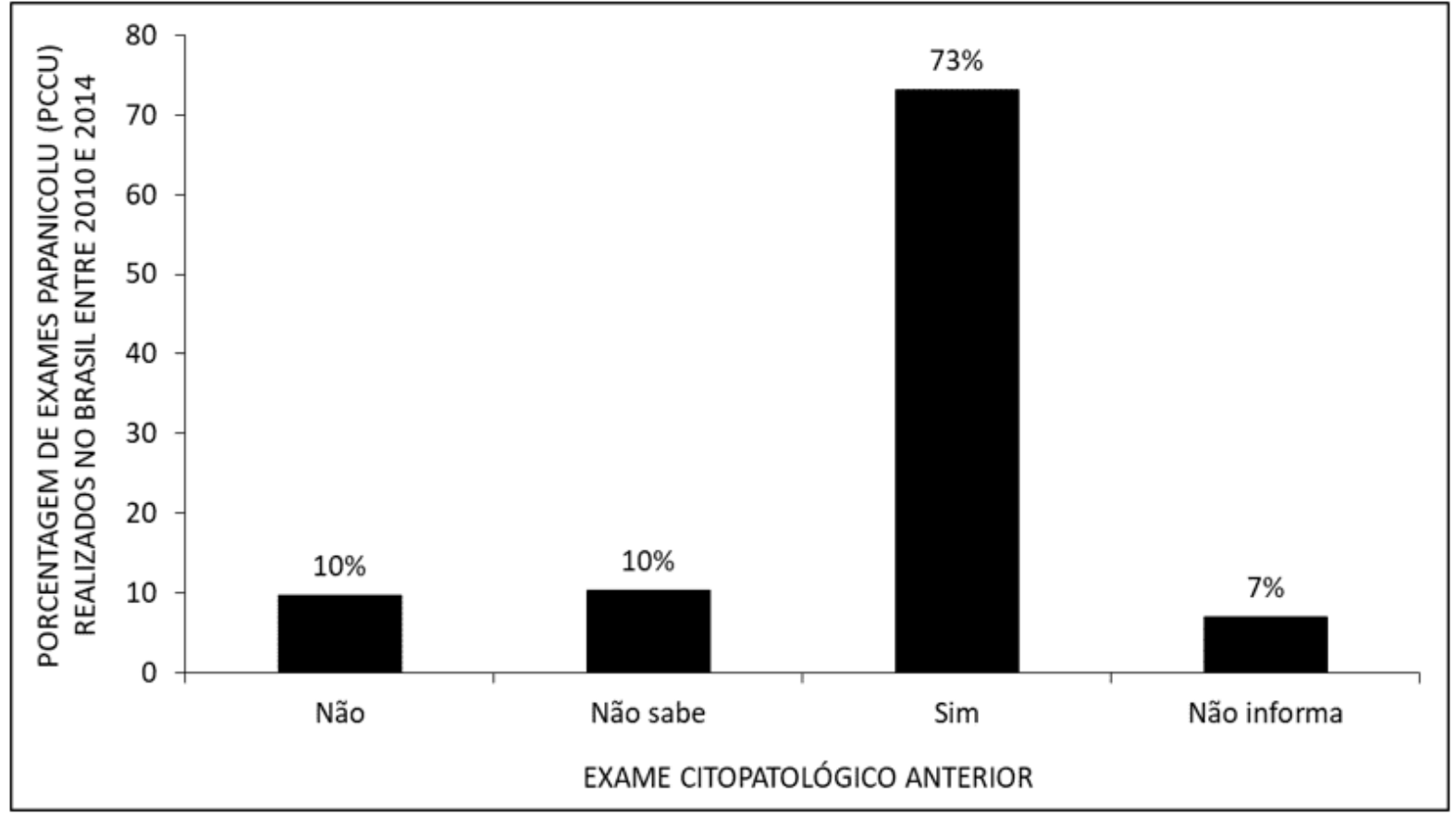

A figura 10 mostra a porcentagem de exames Papanicolau (PCCU) realizados no Brasil entre 2010 e 2014, de acordo com o tempo de realização do último preventivo. Os dados mostram que a maioria das mulheres realizam exames de ano em ano.

RC: 66619

Disponível em: https://www.nucleodoconhecimento.com.br/saude/colo-do-utero 
Figura 10 Mostra a porcentagem de exames Papanicolau (PCCU) realizados no Brasil entre 2010 e 2014, acordo com o tempo de realização do último preventivo.

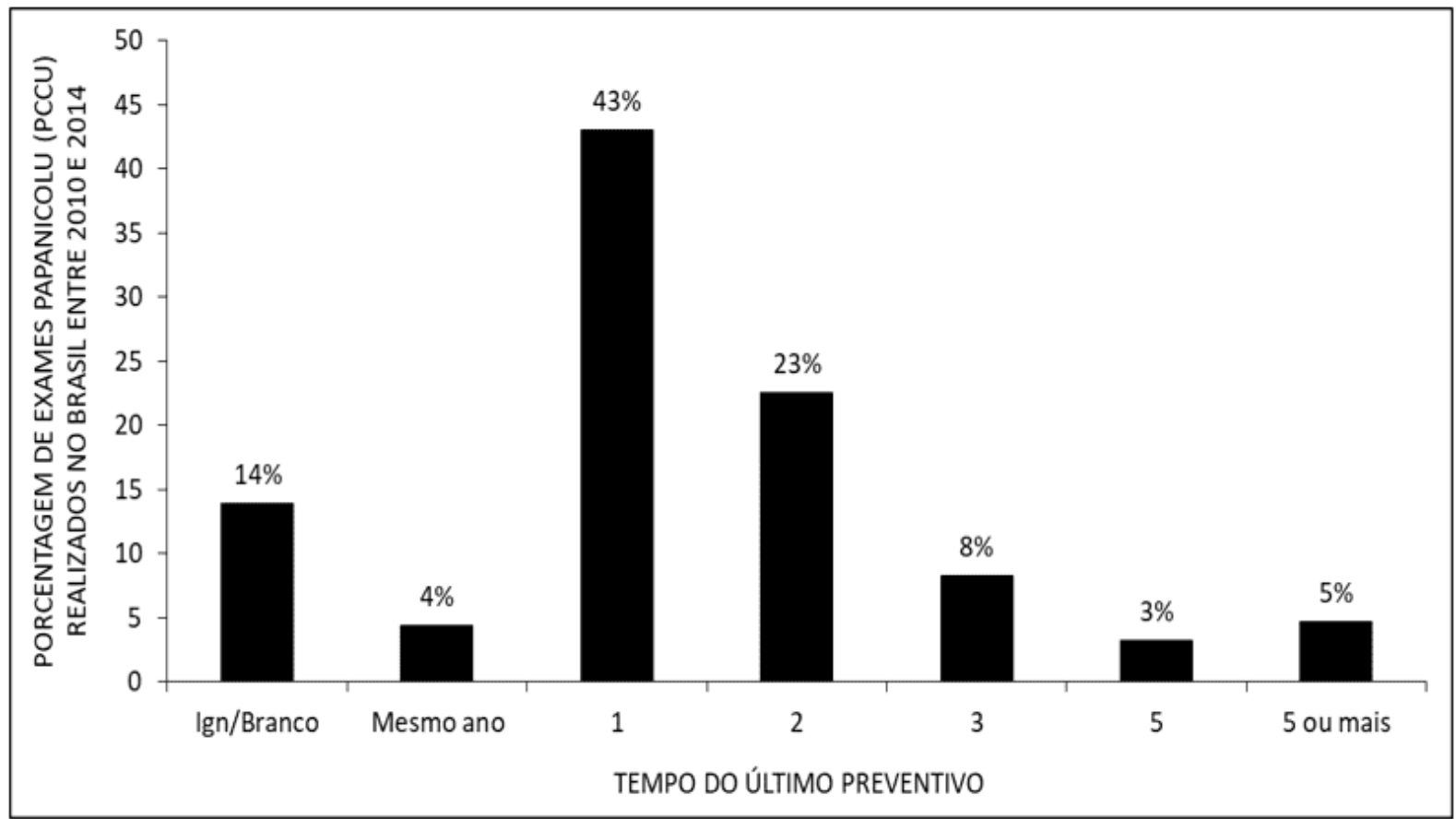

\section{DISCUSSÃO}

Os dados mostram uma diminuição acentuada na realização dos exames no país (figura 1). Alguns fatores parecem influenciar nessa diminuição, como falta de conhecimento da importância do exame e medo deste; vergonha da exposição dos órgãos genitais; dificuldade de acesso às UBSs; falta de preparo dos profissionais quanto ao respeito, orientação e informação prestadas às pacientes sobre o exame (SANTOS e VARELA, 2015).

Os dados mostram maior índice de realização de exames na região sudeste e uma menor quantidade de exames nas regiões nordeste, sul, centro oeste e norte, respectivamente (figura 2). Isto se dá pelo conhecimento, informação e conscientização das mulheres para com o tratamento de prevenção do câncer de colo uterino. Já nas demais regiões teve baixa positividade de exames. Em decorrência disto, o Amapá que fica na Região Norte, constatou menor realização de

RC: 66619

Disponível em: https://www.nucleodoconhecimento.com.br/saude/colo-do-utero 
exames chegando a um percentual menor que $1,0 \%$ de positividade. Assim como nas regiões nordeste, sul e centro-oeste. Notou-se que essas regiões não tiveram participações e conscientização das mulheres, pois o baixo conhecimento científico quanto a realização do exame é um fator que, de qualquer forma pode dificultar a procura pela realização do exame pccu. Alguns motivos justificam este fato, como, vergonha, sentimento de medo, constrangimento durante a realização do exame, falta de tempo, falta de interesse e falta de informações sobre o exame citopatológico (BORTOLON et al., 2012).

Os dados mostram que a maior quantidade de exames é realizada entre mulheres de 30 a 39 anos e a menor quantidade entre mulheres até 19 anos (figura 3). O início da coleta de exames deve ser aos 25 anos de idade independente se a paciente tem vida sexual ativa ou não. Grande quantidade do exame papanicolau é realizado nas faixas etárias de 30 a 39 anos, segundo mostra a tabela. A realização do exame deve seguir até os 64 anos e devem ser interrompidos após a realização de dois exames cujos os resultados dêem negativos, deve-se realizar dois exames com tempos de intervalos de um a três anos. Todas as mulheres que têm vida sexual ativa ou maior de 18 anos é apta a realizar o exame preventivo pccu, porém este exame ainda não é totalmente adquirido pelas Brasileiras, sabe-se que o Brasil tem um alto índice de mortalidade de câncer no colo do útero. Isso ocorre porque grande parte das mulheres procuram tratamento em um grau mais avançado, que na maioria das vezes encontra-se em mulheres na faixa etária de 30 a 39 anos de idade. Conforme a tabela 3 analisou-se que a menor quantidade de exames realizados está entre as mulheres de 19 anos, justamente pela falta de informações sobre o exame pccu e o medo da realização do mesmo (BRASIL,2014).

A maioria das mulheres que realizam o exame tem ensino fundamental incompleto e a minoria ensino superior completo (figura 4). Nesta tabela notou-se que quanto mais estudos e formação escolar as mulheres têm, menos elas têm interesse em realizar o exame preventivo pccu. O motivo para esse resultado está relacionado com as crenças e atitudes em saúde. $29,6 \%$ relatam que não lembraram o porquê

$\mathrm{RC}: 66619$

Disponível em: https://www.nucleodoconhecimento.com.br/saude/colo-do-utero 
não compareceram ao exame. Alguns motivos se dão por medo, vergonha, desconforto e dor. Obtivemos resultados inesperados na tabela 4, pois notamos um alto índice de quantidade de exames pccu realizados por mulheres que têm o ensino fundamental incompleto porque geralmente, mulheres que não tem escolaridade incompleta tendem a construir famílias mais cedo, e em decorrência disso, elas têm mais filhos do que as mulheres que têm um grau de escolaridade maior. Consequentemente estas mulheres vão ao médico com mais frequência obtendo um alto índice de realização do exame papanicolau (SILVA et al.,2015).

As mulheres de etnia branca e parda realizam uma grande quantidade de exames comparadas às mulheres das etnias preta, amarela e indígena (figura 5). Percebeuse que grande parte da não realização do exame papanicolau está associado a etnia, e grande parte dessa resistência está relacionada a fatores como desigualdades de raça/etnias, como em relação ao acesso restrito que determinada raça tem. Conforme mostra a tabela (5). Contudo a baixa cobertura e falta de acessibilidade entre os demais grupos, explica-se pelo acesso e tratamento diferenciado que elas têm ao chegarem ao local de realização do exame (PINHO E JUNIOR, 2003).

Os dados mostram que a maioria dos exames realizados não se encontram dentro da normalidade (figura 6). Grande parte da população feminina encontra se fora da normalidade ao realizar o exame papanicolau. Isso ocorre porque as mulheres procuram realizar o exame em um estado um pouco mais avançado. Isso se explica também, pelo fato de a maioria das mulheres terem mais de um parceiro sexual, havendo tendências a contrair o HPV (Papilomavírus humano), doença sexualmente transmissível. Onde pode haver a desorganização celular no tecido que compõe o colo uterino (NORONHA et al., 2005; OLIVEIRA et al., 2016)).

Os exames foram coletados na sua maioria no intervalo de até 10 dias e a menor quantidade tem um intervalo de coleta maior que 30 dias (figura 7 ). 0 intervalo de coleta, na maioria das vezes é menor e tem duração de intervalo de 10 dias úteis. $\mathrm{O}$ profissional faz a leitura da lâmina e impressão do resultado nesse período, a coleta

$\mathrm{RC}: 66619$

Disponível em: https://www.nucleodoconhecimento.com.br/saude/colo-do-utero 
do exame pccu é realizada durante uma consulta ginecológica, e durante a consulta é inserido um espéculo vaginal sem nenhuma ação de lubrificante, podendo causar um pequeno desconforto. Antes de fazer a coleta a paciente não deve ter relações sexuais no dia anterior. Deve ser realizado fora do período menstrual para obter um resultado mais eficaz (BRITO e NERY, 2007).

A maioria dos resultados foram liberados em até 10 dias e a menor quantidade em mais de 30 dias (figura 8 ). Em relação ao papanicolau $46,55 \%$ das mulheres realizam o exame. Porém $57,8 \%$ realizam em redes particulares, e os resultados do exame são bem mais rápidos, quanto que o resultado das mulheres que realizam o exame pccu pela rede SUS que tem um tempo de entrega maior que o esperado (MURATA et al., 2012).

A maioria das mulheres pesquisadas realizaram exames anteriormente (figura 9). Dentre as mulheres que tem conhecimento sobre o exame pccu, a maior parte dessas realizam o exame com frequência, ou já realizaram anteriormente. Acreditando que com a realização do exame pccu em determinados períodos irão evitar, assim, doenças futuras, como o câncer de colo uterino. Pois é um exame eficaz que se for diagnosticado no início, pode ter $100 \%$ de chances de cura (BARBEIRO et al.,2009).

Os dados mostram que a maioria das mulheres realizam exames de ano em ano (figura 10). Grande parte das mulheres vão ao médico para realizar o exame de câncer do colo do útero com a intenção de prevenir doenças, e tratá-las no início, para evitar problemas no futuro. Recomenda-se fazer a realização do exame pccu anualmente, de ano em ano, para analisar e avaliar se houve ou ocorreu alguma alteração conforme foi o resultado do exame anterior. As mulheres que se preocupam com a sua saúde realizam o exame com períodos de tempos em 1 a dois anos, conforme mostra a figura (10) (PINHO e JUNIOR, 2003; MELO et al., 2019).

RC: 66619

Disponível em: https://www.nucleodoconhecimento.com.br/saude/colo-do-utero 


\section{CONCLUSÃO}

Este estudo mostrou que quando existe um bom desempenho para prevenir uma doença considerada grave, o resultado é satisfatório e eficaz. É importante que tenham divulgações e informações sobre o exame preventivo, porém sabe-se que a prevenção em si é feita apenas com a realização do exame papanicolau para detectar precocemente o nível do grau que o câncer se encontra. Que quando tratado no início tem grandes chances de cura.

Através dos resultados obtidos pela análise dos dados entre os anos de 2010 a 2014 respectivamente, conclui-se que ao passar dos anos a procura pela realização do exame aumentou gradativamente, porém alguns aspectos persistiram, como a vergonha de realizar o exame pcc, medo, dores, entre outros. Contudo os resultados mostraram alto índice realização de exames na região sudeste e menor índice na região norte. Os dados mostram baixa divulgação e pouca conscientização para as mulheres da região norte. Portanto a divulgação, conscientização e realização do exame citopatológico é muito importante para a prevenção do câncer do colo uterino, que hoje em dia é a maior causa de mortalidade entre as mulheres brasileiras

\section{REFERÊNCIAS}

ARAÚJO, R.M.; CUNHA, H.C.O.; FERREIRA, V.G.C.; TRINDADE, M.P.; SOUZA, H.S.L. a importância da realização do exame papanicolau como instrumento de prevenção do câncer de colo do útero: uma revisão integrativa de literatura, Anais do V Congresso de Educação em Saúde da Amazônia. COESA. Universidade Federal do Pará. 2359-084. 2016.

BARBEIRO, F.M.S.; CORTEZ, E.A.; OLIVEIRA, P.A.M.C.; SILVA, A.L.O.; conhecimentos e práticas das mulheres acerca do exame papanicolau e prevenção do câncer cérvico-uterino. Cuidado é fundamental. 1(2):414-422. 2009.

RC: 66619

Disponível em: https://www.nucleodoconhecimento.com.br/saude/colo-do-utero 
BORTOLON, P.C.; SILVA, M.A.F.; CORRÊA, F.M.; DIAS, M.B.K.; KNUPP, V.M.A.; ASSIS, A.; CLARO, I.B. Avaliação da Qualidade dos Laboratórios de Citopatologia do Colo do Útero no Brasil. Revista Brasileira de Cancerologia. 58(3),435444,2012 .

BRASIL. Ministério da Saúde. Secretaria de Atenção à Saúde. Departamento de Atenção Básica. Controle dos cânceres do colo do útero e da mama / Ministério da Saúde, Secretaria de Atenção à Saúde, Departamento de Atenção Básica. - 2. ed. - Brasília: Editora do Ministério da Saúde, 2014. 124 p.

BRASIL. Ministério da Saúde. Secretaria de Atenção à Saúde. Departamento de Atenção Básica. Controle dos cânceres do colo do útero e da mama. Ministério da Saúde. 2. ed. - Brasília: Editora do Ministério da Saúde. 124 p. 2013.

MELO, Carolina Simas. Et al. Caracterização epidemiológica dos óbitos no Brasil por macrorregião de 2016 a 2018. Revista Científica Multidisciplinar Núcleo do Conhecimento. Ano 04, Ed. 12, Vol. 01, pp. 05-17, 2019. Link de acesso: https://www.nucleodoconhecimento.com.br/saude/obitos-no-brasil

MENETRIER, J.V.; BOING, A.; MEDEIROS, K.A. Alterações citopatológicas do colo uterino em mulheres atendidas na 8a Regional de Saúde do Paraná no ano de 2014. Espaço para a Saúde - Revista de Saúde Pública do Paraná. V. 17, n. 2, p. 169177, 2016.

MURATA, I.M.H.; GRABRIELLONI, M.C.; SCHIRMER J. Cobertura do Papanicolau em mulheres de 25 a 59 anos de Maringá - PR, Brasil. Rev Bras Cancerol.58(3):409-15, 2012.

NORONHA, V.L.; NORONHA, R.; CARMONA, B.; MACEDO, L.A.; CRUZ, E.M.; NAUM, C.; MELLO, W.; VILLA, L. Papilomavírus humano (hpv) em mulheres com citologia oncótica dentro dos limites da normalidade. ARTICLE. 17(1): 49-55, 2005.

RC: 66619

Disponível em: https://www.nucleodoconhecimento.com.br/saude/colo-do-utero 
OLIVEIRA, R.C.E.. et. al. Perfil epidemiológico do HPV da população feminina sexualmente ativa, na faixa etária de 10 a 80 anos. Revista Científica Multidisciplinar Núcleo do Conhecimento. Ano 01, Ed. 07, Vol. 04, pp. 21-34, 2016. Link de acesso: https://www.nucleodoconhecimento.com.br/saude/hpv

PINHO, A.A; JUNIOR, I.F. Prevenção do câncer de colo do útero: um modelo teórico para analisar o acesso e a utilização do teste de Papanicolaou. Rev. Bras. Saude Mater. Infant. n.1 Recife jan./mar. 2003.

RICO, A.M.; SILVA, G.A.; LOWY, I.; TEIXEIRA, L. (Org.) et al. Câncer de mama, câncer de colo de útero: conhecimentos, políticas e práticas. Outras Letras. 256 p. 2015.

SANTOS, A.C.S.; VARELA, C.D.S. Prevenção do câncer de colo uterino: motivos que influenciam a não realização do exame de papanicolaou. Revista Enfermagem Contemporânea. 4(2):179-188, 2015.

SILVA, M.A; TEIXEIRA, E.M.B; FERRARI, R.A.P; CESTARI, M.E.W; CARDELLI, A.M. Fatores relacionados a não adesão à realização do exame de Papanicolau. Rev Rene. 16(4).532-9. 2015.

Enviado: Novembro, 2020.

Aprovado: Novembro, 2020.

RC: 66619

Disponível em: https://www.nucleodoconhecimento.com.br/saude/colo-do-utero 